http://jmscr.igmpublication.org/home/

ISSN (e)-2347-176x ISSN (p) 2455-0450

crossref DOI: https://dx.doi.org/10.18535/jmscr/v7i10.161

Journal Of Medical Science And Clinical Research

\title{
Cornelia - de - Lange Syndrome with Infantile Spasms - A Rare Case Report
}

\author{
Authors \\ Swati Pradhan ${ }^{1 *}$,Subhash Chandra Majhi ${ }^{2}$, Piyush Shukla ${ }^{3}$ \\ ${ }^{1} \mathrm{PG}$ Resident ${ }^{2}$ Associate Professor ${ }^{3} \mathrm{PG}$ Resident \\ Department of Paediatrics VIMSAR Burla Sambalpur Odisha, India \\ *Corresponding Author \\ Swati Pradhan \\ Room No 119 Ladies Hostel, VIMSAR Burla Sambalpur, India
}

\section{Introduction}

Cornelia de-Lange syndrome (CdLS) was first described as a distinct syndrome in 1933, by Dr Cornelia de-Lange, a Dutch paediatrician, after whom the disorder has been named, though the first ever documented case was in1916 by Dr Brachmann. ${ }^{(1)}$ It is a rare genetic disorder characterised by facial dysmorphia (arched eyebrows, synophrys, depressed nasal bridge, long philtrum, down-turned angles of the mouth), upper-extremity malformations, hirsutism, cardiac defects, growth and cognitive retardation, and gastrointestinal abnormalities. ${ }^{(2)}$ Seizure is found about $20 \%$ of cases majority being partial seizure type $(64.3 \%){ }^{(3)}$

\section{Case Report}

We report a 6 months old male child presented to our hospital VIMSAR Burla with complains of brief jerky abnormal movement of head neck arms and legs simultaneously for 5 days and not attending head control since birth. He was born at 39 weeks of gestation through normal vaginal delivery birth weight was $2.5 \mathrm{~kg}$ cried immediately after birth and no history of neonatal hospitalisation. Physical Examination revealed flat occiput well defined and arch like eye brows, synophrys, long curly eye lashes, hypertelorism, depressed nasal bridge with anteverted nares, high arched palate thin lips with downturned angles of mouth long philtrum, micrognathia, hirsutism small broad hands and legs. Cardiovascular Examination shows no murmur with head lag in CNS.

Fig 1 - Characteristic EEG findings in Infantile Spasms associated with Cornelia - de Lange Syndrome-Hypsarrythmia 


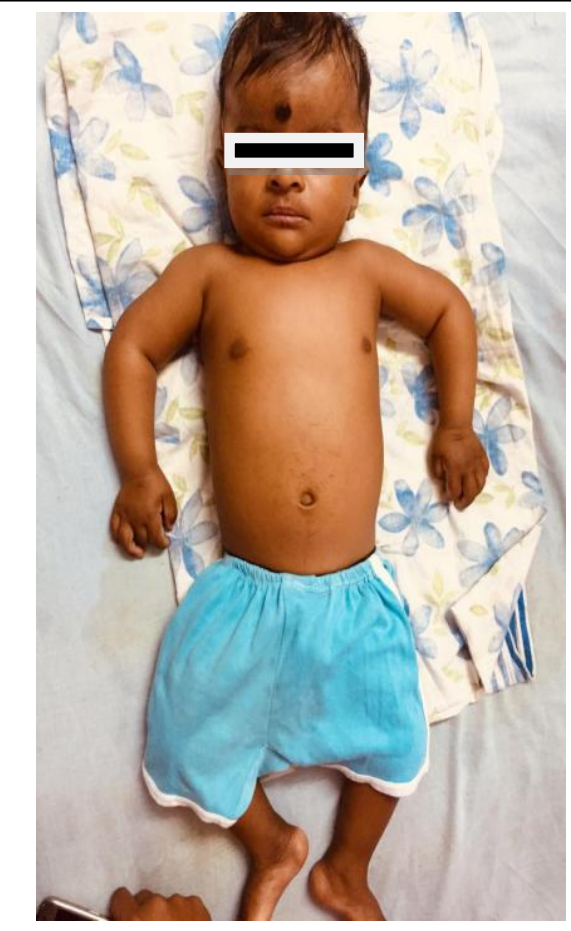

Fig 2 - Body dysmorphism in Cornelia- de Lange Syndrome

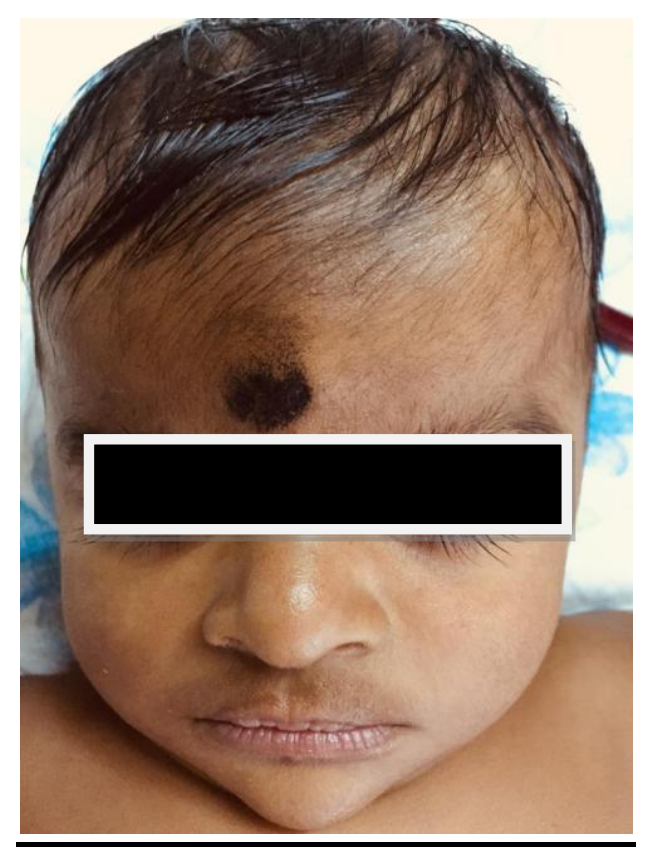

Fig 3 - Characteristic facial features of Cornelia de lange Syndrome

\section{Discussion}

Cornelia de Lange syndrome is a rare genetic disease, caused by mutations in three known different genes: NIBPL (crom 5p), SMC1A (crom $\mathrm{X}$ ) and SMC3 (crom 10q), that account for about $65 \%$ of cases. ${ }^{(4)}$ Partial epilepsy is the most common type of epilepsy in CdLS patients. In the majority of cases the prognosis of this epilepsy is favourable and therapy can be withdrawn after few years of complete seizure control. ${ }^{(3)}$ There is no data about association about infantile spasms with CDLS. Infantile spasms are epileptic spasms that occur in infancy or early childhood. These spasms are classically characterized clinically by symmetric, brief jerking spells that involve the head, neck, arms, legs, and abdomen which may consist of flexion, extension, or a combination of flexion-extension. Infantile spasms often are associated with a characteristic pattern on electroencephalogram (EEG) called hypsarrhythmia. ${ }^{(5)}$

\section{Conclusion}

CDLS is a rare congenital multisystem disorder having seizure as a rare presentation. Partial epilepsy is the most common type of epilepsy in CDLS with specific focal EEG changes. CDLS patients with Infantile Spasm is very rare combination sometimes Paediatric Neurologists may be the first health personnel to identify such cases. Multidisciplinary treatment approach is the key to managing child with CDLS with Infantile Spasms.

\section{References}

1. Mehta DN, Bhatia R. Cornelia de-lange syndrome: a case report. Int J Clin Pediatr Dent. 2013 May; 6(2):115-8. doi: 10.5005/jp-journals-10005-1201. Epub 2013 Aug 26. PMID: 25206204; PMCID: PMC4086580.

2. Uzun H, Senses DA, Uluba M, Kocabay K. A newborn with Cornelia de Lange syndrome: a case report. Cases J. 2008;1(1):329. Published 2008 Nov 19. doi:10.1186/1757-1626-1-329

3. Epilepsy in patients with Cornelia de Lange syndrome: A clinical series Verrotti, Alberto et al. Seizure - European Journal of Epilepsy, Volume 22, Issue 5, 356 359 
4. Epileptic features in Cornelia de Lange syndrome: Case report and literature review Pavlidis, Elena et al. Brain and Development, Volume 36, Issue 10, 837 843

5. Xixis KL, Jain S. Infantile Spasm (West Syndrome) [Updated 2019 Jun 4]. In: Stat Pearls [Internet]. Treasure Island (FL): Stat Pearls Publishing; 2019 Jan-. Available from:

https://www.ncbi.nlm.nih.gov/books/NBK 448139/ 